\title{
Letter to the Editor: Chikungunya Virus Infection-An Update on Chronic Rheumatism in Latin America
}

\author{
Alfonso J. Rodriguez-Morales* \\ Public Health and Infection Research Group, Faculty of Health Sciences, Universidad Tecnologica de \\ Pereira, Pereira, Risaralda, Colombia; and Colombian Collaborative Network on Zika and Other \\ Arboviruses (RECOLZIKA), Pereira, Risaralda, Colombia
}

\section{To the Editor,}

The article of Krutikov and Manson ${ }^{1}$ was interesting. However, no comment was made on the impact and related clinical epidemiology of the chikungunya virus (CHIKV) infection during the 2014-2015 epidemics in Latin America, the most recent area affected by CHIKV. Certainly, persistent musculoskeletal manifestations of the disease have been shown to affect a highly variable proportion of infected patients (even $>87 \%$ ). Following the epidemics in La Réunion Island and India, ${ }^{2}$ and now in Latin America, this disease is having a significant impact.

That impact should be obvious when considering the officially reported cases: over 2 million were noted in the Americas between 2014 and 2016.3 Nevertheless, in countries such as Colombia (with over 1 million cases officially reported), final estimations indicate that over 3 million cases of CHIKV infection were detected. During 2014, as epidemics began in the region, initial estimates of the potential impact were based primarily on the experience in La Réunion and India. These data provided an expected prevalence of $47.57 \%$ for post-chikungunya chronic inflammatory rheumatism (pCHIKV-CIR) (95\% CI $45.08 \%-50.13 \%) .4$

In Colombia, the Sucre department (state) 5 published a first study in the Americas in August 2015 with information about a small cohort $(n=39)$ that was followed for a median of 37 weeks; $89.7 \%$ (95\% CI 75.8\%-97.1\%) of those followed developed pCHIKV-CIR. Also in August 2015, Colombia's Tolima department provided data on a larger study $(n=131)$. Over a 24-week follow-up period the pCHIKV-CIR prevalence was $44.3 \% \quad$ (95\%CI $35.39 \%-53.16 \%$ ), being higher in women over 40 years of age $(52.3,95 \%$ CI $36.38 \%-68.17 \%){ }^{6}$ In

\footnotetext{
Abbreviations: CHIKV, chikungunya virus; pCHIKV-CIR, post-chikungunya chronic inflammatory rheumatism.

Citation: Rodriguez-Morales, AJ. Letter to the Editor: Chikungunya Virus Infection-An Update on Chronic Rheumatism in Latin America. Rambam Maimonides Med J 2017;8 (1):eo013. doi:10.5041/RMMJ.10288

Copyright: (C) 2017 Rodriguez-Morales. This is an open-access article. All its content, except where otherwise noted, is distributed under the terms of the Creative Commons Attribution License (http://creativecommons.org/licenses/by/3.0), which permits unrestricted use, distribution, and reproduction in any medium, provided the original work is properly cited.
}

Conflict of interest: No potential conflict of interest relevant to this article was reported.

* E-mail: arodriguezm@utp.edu.co 
March 2016, an even larger Latin American study ( $n=283$ ), from Colombia's Risaralda department, was published showing that $53.7 \%$ (95\% CI $47.7 \%-$ $59.7 \%$ ) of patients presented with pCHIKV-CIR in a median time of 14.6 weeks. 7 By pooling together the data from studies in Colombia, a combined prevalence of pCHIKV-CIR of $56.6 \%$ is obtained ( $95 \% \mathrm{CI}$ $40.5 \%-72.6 \% ; n=453 ; I^{2}=75.3 ; Q=8.1$ ).

Hence, this disease can last for months and years, and presents important concerns about the associated disability (estimated as disabilityadjusted life years (DALYs) lost), which have already been assessed in Latin America. Countries such as the Dominican Republic, El Salvador, Puerto Rico, and Colombia are among the most affected ( $>30$ DALYs lost per 100,000 population). ${ }^{8,9}$ In 2014 alone, Colombia estimated that the cost of CHIKV infection to the country will be in the magnitude of 73.6 million dollars, up to 185.6 million dollars, ${ }^{10}$ with regions showing $>2,800$ DALYs lost per 100,000 population (San Juan de Nepomuceno, Bolivar). ${ }^{10}$

Many questions remain on the multiple clinical aspects of pCHIKV-CIR. As Krutikov and Manson ${ }^{1}$ already stated, the etiology of this arthralgia is not fully understood and requires more research. Undoubtedly, CHIKV has become a major threat, particularly in Latin America, where-despite efforts to control the disease better-transmission still occurs, with more than 300,000 new cases detected in the region in 2016.

\section{REFERENCES}

1. Krutikov M, Manson J. Chikungunya virus infection: an update on joint manifestations and management. Rambam Maimonides Med J 2016;7:eo033. Full Text

2. Rodríguez-Morales AJ, Cardona-Ospina JA, UrbanoGarzón SF, Hurtado-Zapata JS. Prevalence of postChikungunya chronic inflammatory rheumatism: a systematic review and meta-analysis. Arthritis Care Res (Hoboken) 2016;68:1849-58. Full Text
3. Rodríguez-Morales AJ, Villamil-Gómez WE, FrancoParedes C. The arboviral burden of disease caused by co-circulation and co-infection of dengue, chikungunya and Zika in the Americas. Travel Med Infect Dis 2016;14:177-9. Full Text

4. Rodriguez-Morales AJ, Cardona-Ospina JA, VillamilGómez W, Paniz-Mondolfi AE. How many patients with post-chikungunya chronic inflammatory rheumatism can we expect in the new endemic areas of Latin America? Rheumatol Int 2015;35:2091-4. Full Text

5. Rodriguez-Morales AJ, Villamil-Gomez W, MerlanoEspinosa M, Simone-Kleber L. Post-chikungunya chronic arthralgia: a first retrospective follow-up study of 39 cases in Colombia. Clin Rheumatol 2016;35:831-2. Full Text

6. Rodríguez-Morales AJ, Calvache-Benavides CE, Giraldo-Gómez J, et al. Post-chikungunya chronic arthralgia: results from a retrospective follow-up study of 131 cases in Tolima, Colombia. Travel Med Infect Dis 2016;14:58-9. Full Text

7. Rodriguez-Morales AJ, Gil-Restrepo AF, RamírezJaramillo V, et al. Post-chikungunya chronic inflammatory rheumatism: results from a retrospective follow-up study of 283 adult and child cases in La Virginia, Risaralda, Colombia. Version 2. F10ooRes. 2016 Mar 16 [revised 2016 Apr 4];5:360.

8. Cardona-Ospina JA, Rodriguez-Morales AJ, VillamilGómez W. Burden of chikungunya in one coastal department of Colombia (Sucre): estimates of disability adjusted life years (DALY) lost in 2014 epidemic. J Infect Public Health 2015;8:644-6.

9. Cardona-Ospina JA, Diaz-Quijano FA, RodríguezMorales AJ. Burden of chikungunya in Latin American countries: estimates of disability adjusted life years (DALY) lost in 2014 epidemic. Int J Infect Dis 2015;38:60-1. Full Text

10. Cardona-Ospina JA, Villamil-Gómez WE, JimenezCanizales CE, Castañeda-Hernández DM, RodríguezMorales AJ. Estimating the burden of disease and the economic cost attributable to chikungunya, Colombia, 2014. Trans R Soc Trop Med Hyg 2015;109:793802. Full Text 